\title{
Electrogenerated Chemiluminescence. 77. DNA Hybridization Detection at High Amplification
}

with $\left[\operatorname{Ru}(\mathrm{bpy})_{3}\right]^{2+}$-Containing Microspheres

Wujian Miao and Allen J. Bard

\section{Supporting Information:}
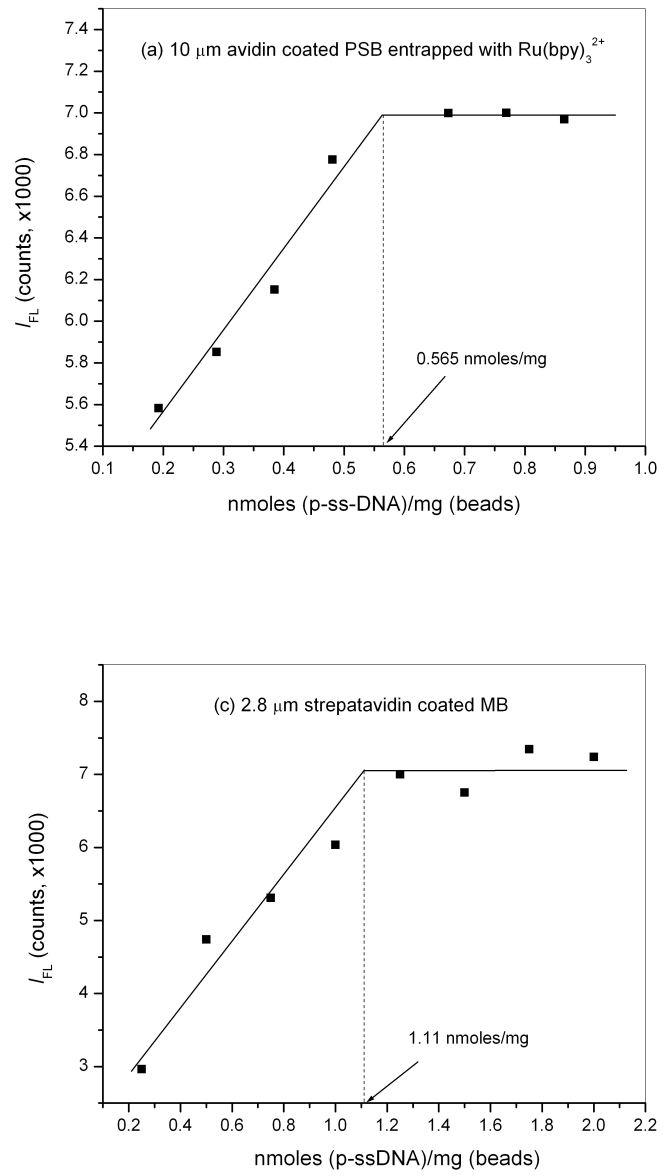

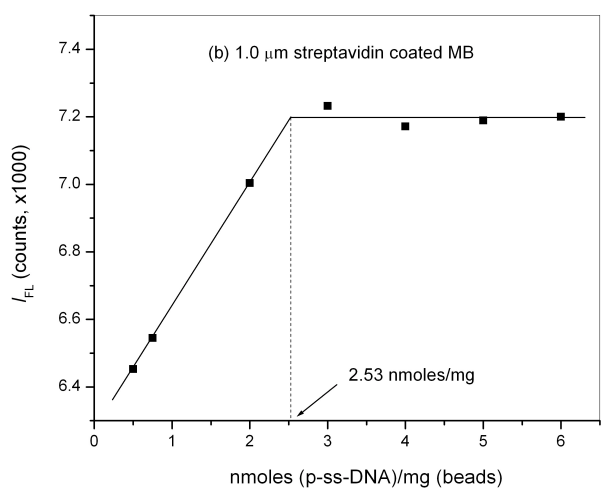

Figure S1. Binding capacities of (a) $10 \square \mathrm{m}$ diameter avidin coated polystyrene beads entrapped with $\mathrm{Ru}(\mathrm{bpy})_{3}{ }^{2+}$, (b) $1.0 \square \mathrm{m}$ diameter streptavidin coated magnetic beads, and (c) $2.8 \square \mathrm{m}$ in diameter streptavidin coated magnetic beads for a biotinylated 23-mer-ss DNA (p-ssDNA) obtained from fluorescein biotin titration experiments. Respectively, a series of 20, 10 and $20 \square \mathrm{L}$ of $10 \square \mathrm{m}$ PSB, 1.0 or $2.8 \square \mathrm{m} \mathrm{MB}$ were mixed with 5 to $60 \square \mathrm{L}$ of $10 \square \mathrm{M}$ p-ssDNA and incubated for $1 \mathrm{~h}$ at R.T. before adding $1.0 \mathrm{~mL}$ of $5 \square 10^{-8} \mathrm{M}$ fluorescein biotin into the mixtures. The supernatant solutions were used for fluorescent measurements at $\square_{\mathrm{ex}}=485 \mathrm{~nm}$ and $\square_{\mathrm{em}}=517 \mathrm{~nm}$ with a PMT 814 fluorometer (Photon Technology International, London, ON, Canada).

Table S1. Summary of Binding Capacities of $10 \square \mathrm{m}$ PSB, $1.0 \square \mathrm{m}$ MB and $2.8 \square \mathrm{m} \mathrm{MB}$

\begin{tabular}{|c|c|c|c|}
\hline \multirow[b]{2}{*}{ Type of Beads } & \multicolumn{2}{|c|}{ Binding Capacity } & \multirow[b]{2}{*}{ Tuning Point } \\
\hline & $\begin{array}{c}\text { p-ssDNA nmoles } \\
\text { per mg beads }\end{array}$ & $\begin{array}{l}\text { p-ssDNA molecules } \\
\text { per bead }\end{array}$ & \\
\hline $10 \square \mathrm{m}$ PSB & 0.565 & $1.4 \square 10^{8}$ & $\begin{array}{c}20 \square \mathrm{L} \text { PSB } ~ 29.4 \square \mathrm{L} \\
\text { of } 10 \square \mathrm{M} \text { p-ssDNA }\end{array}$ \\
\hline $1.0 \square \mathrm{m} \mathrm{MB}$ & 2.53 & $1.6 \square 10^{6}$ & $\begin{array}{l}10 \square \mathrm{L} \mathrm{MB} \sim 25.3 \square \mathrm{L} \\
\text { of } 10 \square \mathrm{M} \text { p-ssDNA }\end{array}$ \\
\hline $2.8 \square \mathrm{m} \mathrm{MB}$ & 1.11 & $1.0 \square 10^{7}$ & $\begin{array}{c}20 \square \mathrm{L} \mathrm{MB} \sim 22.2 \square \mathrm{L} \\
\text { of } 10 \square \mathrm{M} \mathrm{p}-\mathrm{ssDNA}\end{array}$ \\
\hline
\end{tabular}


Table S2. The Poisson distribution data obtained from $P(m, n)=\mathrm{e}^{-m}\left[m^{n} / n !\right]$

\begin{tabular}{|c|l|l|l|l|l|l|l|l|l|}
\hline \multirow{2}{*}{$n$} & \multicolumn{9}{|c|}{$m$} \\
\cline { 2 - 10 } & 1 & 2 & 3 & 4 & 5 & 6 & 8 & \multicolumn{1}{|c|}{10} & 12 \\
\hline 0 & 0.36788 & 0.13534 & 0.049787 & 0.018316 & 0.0067379 & 0.0024788 & 0.00033546 & $4.5400 \mathrm{e}-05$ & $6.1442 \mathrm{e}-06$ \\
1 & 0.36788 & 0.27067 & 0.14936 & 0.073263 & 0.033690 & 0.014873 & 0.0026837 & 0.00045400 & $7.3731 \mathrm{e}-05$ \\
2 & 0.18394 & 0.27067 & 0.22404 & 0.14653 & 0.084224 & 0.044618 & 0.010735 & 0.0022700 & 0.00044238 \\
3 & 0.061313 & 0.18045 & 0.22404 & 0.19537 & 0.14037 & 0.089235 & 0.028626 & 0.0075667 & 0.0017695 \\
4 & 0.015328 & 0.090224 & 0.16803 & 0.19537 & 0.17547 & 0.13385 & 0.057252 & 0.018917 & 0.0053086 \\
5 & 0.0030657 & 0.036089 & 0.10082 & 0.15629 & 0.17547 & 0.16062 & 0.091604 & 0.037833 & 0.012741 \\
$\ldots$ & $\ldots$ & $\ldots$ & $\ldots$ & $\ldots$ & $\ldots$ & $\ldots$ & $\ldots$ & $\ldots$ & $\ldots$ \\
\hline Sum & 1 & 1 & 1 & 1 & 1 & 1 & & & \\
\hline
\end{tabular}

